\title{
Room-Temperature Humidity Sensing Using Graphene 0xide Thin Films
}

\author{
Gautam Naik, Sridhar Krishnaswamy \\ Center for Quality Engineering, Northwestern University, Evanston, USA \\ Email: s-krishnaswamy@northwestern.edu
}

Received 16 October 2015; accepted 30 November 2015; published 3 December 2015

Copyright (C) 2016 by authors and Scientific Research Publishing Inc.

This work is licensed under the Creative Commons Attribution International License (CC BY). http://creativecommons.org/licenses/by/4.0/

(c) (i) Open Access

\begin{abstract}
In this article, we report on a room-temperature humidity sensing device using graphene oxide (GO) thin films synthesized by chemical exfoliation. Changes in the device conductivity are measured for varying relative humidity in the experimental chamber. Experiments are carried out for relative humidity varying from $\mathbf{3 0 \%}$ to $\mathbf{9 5 \%}$. We observe a difference in the results obtained for low relative humidity $(<50 \%)$ and high relative humidity $(>50 \%)$, and propose a sensing mechanism to explain this difference. Although the sensor exhibits some hysteresis at high relative humidities, a method to "reset" the sensor is also proposed. The sensing device has high sensitivity and fast response time.
\end{abstract}

\section{Keywords}

Graphene, Thin Film, Sensor, Humidity, Hysteresis

\section{Introduction}

Humidity sensors are in demand in the industrial, environmental, and structural monitoring fields. One of the most frequent causes of structural failure is corrosion. A large number of structures degrade and fail due to inefficient humidity monitoring. A lot of research has been conducted to fabricate high efficiency humidity sensors, based on either change in resistance [1]-[3] or mass [4] [5], of a thin film due to the presence of water molecules. More recently, humidity sensors for corrosion detection were fabricated using long period gratings by calculating the resonant wavelength shift [6]. In recent years, research has been conducted to achieve a high level of sensitivity and selectivity in sensors. Here especially, carbon-based materials like graphene have raised great interest for various types of applications due to their excellent electronic properties, high levels of thermal conductivity, stiffness and strength, and excellent adsorption properties.

Graphene was first isolated in 2004 [7], and is best described as a two-dimensional single-atom thick sheet of $\mathrm{sp}^{2}$ hybridized carbon atoms arranged in a honeycomb lattice, and is the basic building block for all graphitic 
materials [8]. Schedin et al. were one of the first to demonstrate the potential of using graphene for detection of gases [9]. Since then, research has been conducted to demonstrate the use of graphene, and its derivative graphene oxide, to fabricate nanoscale sensors to detect various gases such as $\mathrm{CO}_{2}, \mathrm{NO}_{2}, \mathrm{NH}_{3}$.

Lu et al. demonstrated using thermally-reduced graphene oxide to fabricate high-performance sensors to detect $\mathrm{NO}_{2}$ and $\mathrm{NH}_{3}$ in air [10] [11]. Lange et al. used a graphene-palladium nanoparticle composite to detect hydrogen in air [12]. Nomani et al. achieved high sensitivity and selectivity with sensors fabricated using epitaxial graphene [13]. Jeong et al. fabricated a flexible $\mathrm{NO}_{2}$ sensor based on hybrid films based on carbon nanotubes and graphene [14]. Yoon et al. reported a $\mathrm{CO}_{2}$ gas sensor using graphene fabricated by mechanical cleavage [15]. Robinson et al. demonstrated the use of reduced graphene oxide to detect chemical-warfare agents and explosives at parts-per-billion concentrations [16]. Recently, Hu et al. demonstrated the use of chemically reduced graphene oxide (CRG) for the detection of dimethyl methylphosphonate (DMMP) [17].

A limited amount of work has been done with regards to humidity detection using graphene and graphene oxide. Massera et al. reported using a graphene sheet as a humidity sensor, in which the graphene samples were prepared by the scotch-tape method [18]. Guo et al. used laser-reduced graphene-oxide films for humidity sensing [19], whereas a graphene oxide-silicon bilayer was used for humidity sensing by Yao et al. [20]. These use the change in resistance as the mechanism for sensing humidity. Yao et al. demonstrated the sensitivity of graphene oxide to humidity by using it as a coating on quartz crystal microbalances, which is based on the concept of change in frequency due to a change in mass [21].

However, most of the work done for gas and humidity sensing has been done at the micro- and nanoscale. Taking advantage of the excellent sensitivity and selectivity of nanomaterials such as graphene to fabricate large-area sensors is crucial. The presence of hydroxyl, carbonyl, and carboxyl functional groups on the basal plane of graphene oxide makes it hydrophilic and completely soluble in water. This property of graphene oxide also makes it sensitive to moisture, which can be used to sense humidity in the atmosphere. In this work, we examine the humidity sensing characteristics of large-area graphene oxide thin films. For this purpose, we fabricate humidity sensing devices using graphene oxide synthesized using chemical exfoliation and conduct experiments at various humidity levels. Possible humidity sensing mechanisms of the sensors are also discussed.

\section{Material and Methods}

\subsection{Materials and Equipment}

To prepare graphene oxide, graphite (particle size $40 \mu \mathrm{m})$, sulphuric acid $\left(\mathrm{H}_{2} \mathrm{SO}_{4}, 98 \%\right)$, sodium nitrate $\left(\mathrm{NaNO}_{3}\right)$, potassium permanganate $\left(\mathrm{KMnO}_{4}\right)$, and hydrogen peroxide $\left(\mathrm{H}_{2} \mathrm{O}_{2}, 30\right.$ wt.\%) were obtained from Alfa Aesar. Graphite, $\mathrm{NaNO}_{3}$, and $\mathrm{KMnO}_{4}$ were used as obtained. To dilute $\mathrm{H}_{2} \mathrm{SO}_{4}$ and $\mathrm{H}_{2} \mathrm{O}_{2}$ to required concentrations, Milli-Q deionized water with resistivity of $\sim 18 \mathrm{M} \Omega * \mathrm{~cm}$ was used.

Experiments were carried out in a sealed chamber. To measure conductivity, a Keithley 2400 source meter was used. Humidity was introduced in to the chamber using a commercial mini-humidifier. Milli-Q deionized water was used in the humidifier to ensure high purity of humidity. Relative humidities and temperatures inside the chamber were monitored using a model TH804 commercial humidity monitor manufactured by Nicetu.

\subsection{Sensor Fabrication}

Graphene oxide (GO) was prepared using the Hummers’ method [22]. GO paper samples were prepared using bottle-top vacuum filtration of GO in water through a $47 \mathrm{~mm}$ diameter Whatman Anodisc membrane filter with a pore size of $0.02 \mu \mathrm{m}$. The GO papers were left overnight to dry at room temperature, and then peeled off from the filter.

The humidity sensors were fabricated by cutting out $10 \mathrm{~mm}$ wide, $30 \mathrm{~mm}$ long rectangular samples from the GO papers obtained by filtration. From scanning electron microscope images, the thickness of the samples is obtained to be $\sim 20 \mu \mathrm{m}$, as shown in Figure 1(a). Copper wires (diameter $0.12 \mathrm{~mm}$ ) were bonded as electrodes to the GO samples using Circuit Works conductive epoxy, and left to dry overnight. Figure 1(b) shows some of the humidity sensing devices fabricated.

\subsection{Characterization}

The fabricated GO papers were imaged using a Hitachi scanning electron microscope equipped with secondary 

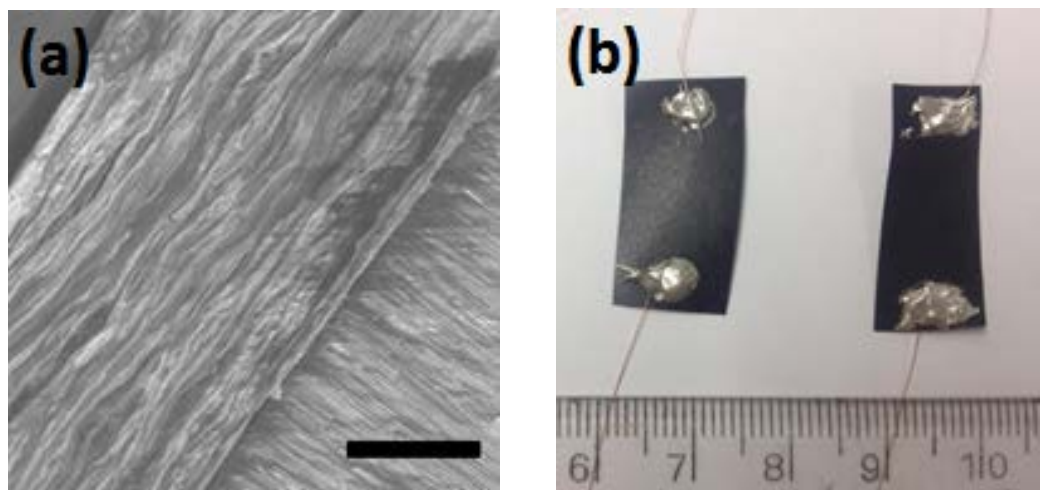

Figure 1. (a) SEM image of device cross-section (Scale bar is 10 microns); (b) Fabricated humidity sensing devices.

electron detectors. Imaging was done at $20 \mathrm{kV}$ acceleration voltage and $10 \mu \mathrm{A}$ emission current. To characterize the atomic weight percentage of different elements present in the GO papers, energy-dispersive X-ray spectroscopy was carried out in the scanning electron microscope. Raman spectra were obtained using a Acton TriVista CRS Confocal Raman System, with a laser wavelength of $514.5 \mathrm{~nm}$. Powder X-ray diffraction spectra were obtained using a Rigaku DMAX diffractometer with $\mathrm{CuK}_{\alpha}$ radiation $(\lambda=1.54056 \AA)$.

\subsection{Humidity Sensing Experiments}

To characterize the performance of the fabricated graphene device as a humidity sensor, we measured the change in its resistance upon exposure to varying relative humidities inside the chamber. The resistance of the film was measured by applying a constant DC voltage of $1 \mathrm{~V}$, and measuring the current. As illustrated in Figure 2, the graphene device is enclosed in a chamber (vol. $~ 9800 \mathrm{~cm}^{3}$ ) with the commercial humidifier and humidity monitor. The copper electrodes are connected to the Keithley 2400 source meter using alligator clips, which might introduce some contact resistance. A controlled test with a known resistance showed less than $0.1 \%$ variability on exposure to humidity. Thus, a change in contact resistance due to humidity is ruled out. The source meter is connected to a PC using a GPIB interface, where the data is acquired using LabVIEW. Figure 2 shows a schematic of the experimental setup. All experiments are carried out at room temperature $\left(24^{\circ} \mathrm{C} \pm 1^{\circ} \mathrm{C}\right)$.

\section{Results and Discussion}

\subsection{Characterization}

Figure 3 shows the powder X-ray diffraction spectra of graphene oxide and graphite. Peak $2 \theta$ angles of $9.6^{\circ}$ and $26.7^{\circ}$ are obtained for graphene oxide and pristine graphite, which correspond to an interlayer spacing of 0.92 and $0.34 \mathrm{~nm}$ respectively. Figure 4 shows the Raman spectra of graphene oxide and pristine graphite. D and G peaks are clearly seen in the spectrum for graphene oxide, with a slight red shift of the G peak towards 1600 $\mathrm{cm}^{-1}$. The Raman Intensity $\left(\mathrm{I}_{\mathrm{D}} / \mathrm{I}_{\mathrm{G}}\right)$ value of 0.96 is obtained for graphene oxide. These values are consistent with previous works [23]-[26]. Elemental characterization of graphene oxide was carried out using energy-dispersive $\mathrm{X}$-ray spectroscopy (Figure 5). Table 1 shows the atomic percentage of elements present in the fabricated GO device. A C/O ratio of 2:1 is obtained, which is consistent with that in literature where $\mathrm{C} / \mathrm{O}$ ratios between 1.15 and 2.5 have been reported [24] [27] [28].

\subsection{Humidity Sensing Experiments}

To characterize the performance of the sensing device, humidity is infused into the chamber using the minihumidifier. Figure 6(a) shows the time response of the GO humidity sensing device, when the humidity was increased from $30 \%$ to $60 \%$. At $90 \mathrm{~s}$ into the data recording, the humidifier is switched ON for $30 \mathrm{~s}$. Infusion of humidity into the chamber decreases the resistance drastically. Figure 6(a) shows the relative resistance of GO after humidity infusion (R) compared to the resistance in ambient air $\left(R_{0}\right)$. $R_{0}$ was found to be about $120 \mathrm{M} \Omega$ for most films. Resistance data is normalized to exclude the variability in resistance between devices and also the slight contact resistance that might be caused due to the use of alligator clips. 


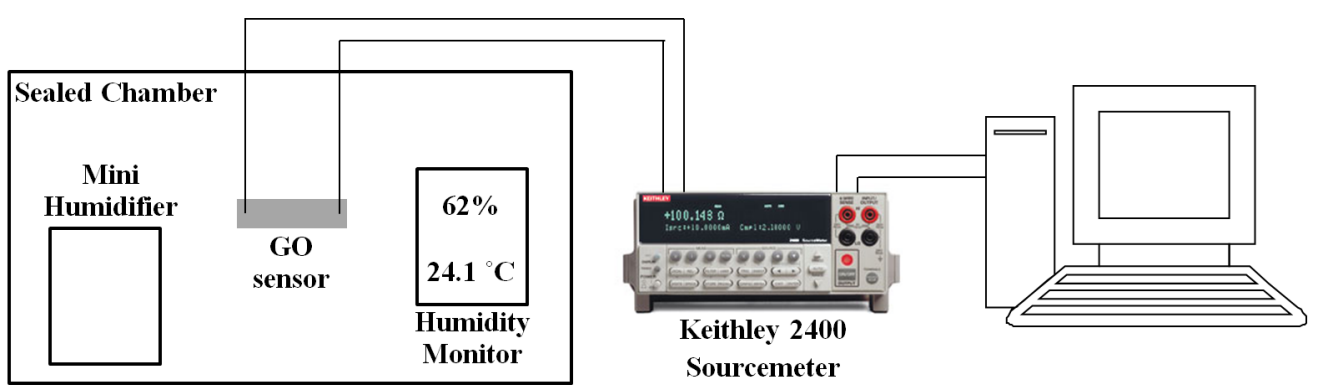

Figure 2. Schematic of experimental setup.

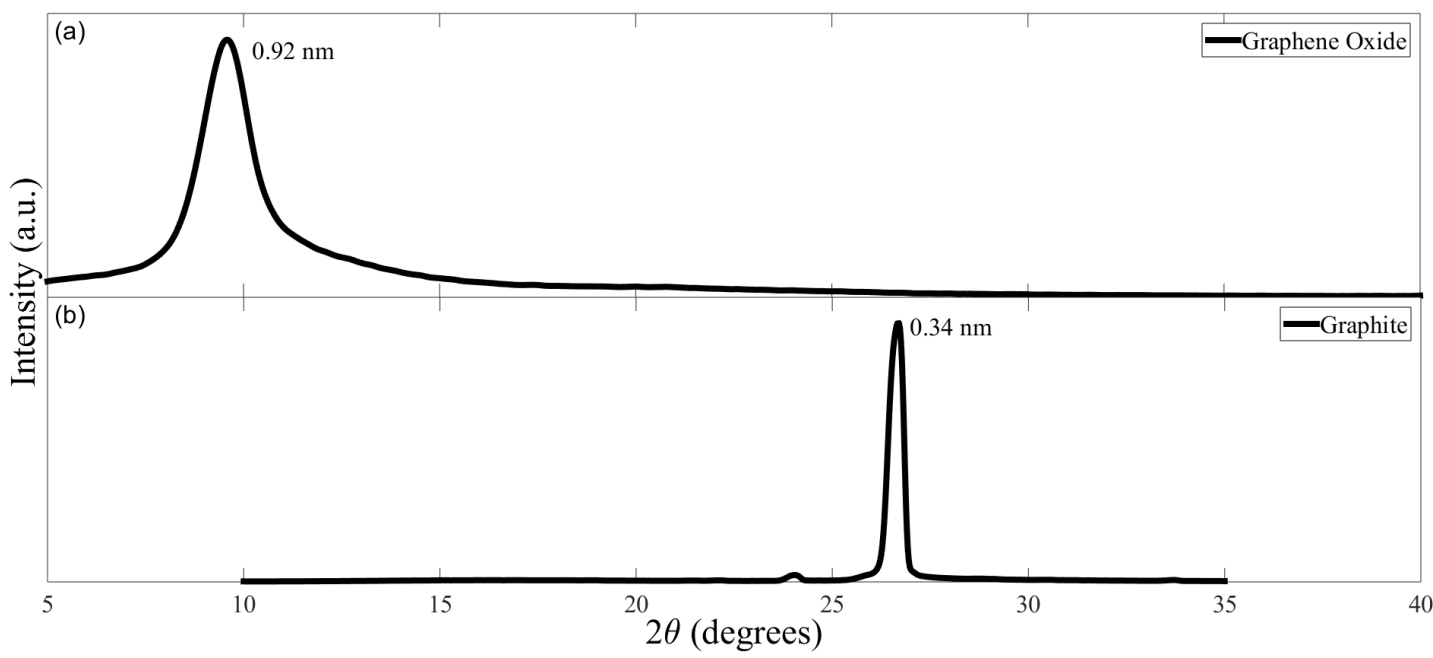

Figure 3. X-ray diffraction spectra of graphene oxide and graphite.

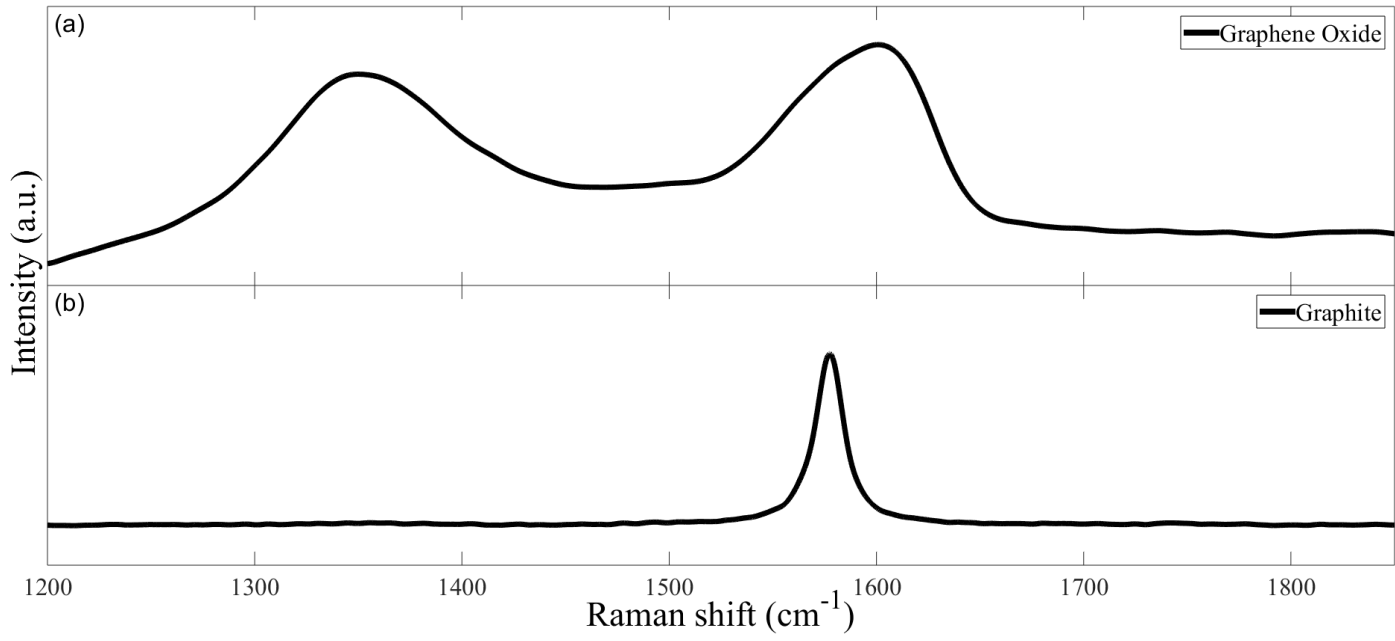

Figure 4. Raman spectra of graphene oxide and graphite.

Table 1. Element analysis of graphene oxide.

\begin{tabular}{cc}
\hline Element & Atomic \% \\
\hline Carbon & 65.93 \\
Oxygen & 33.34 \\
Others (Mn, S, K, etc.) & 0.73
\end{tabular}




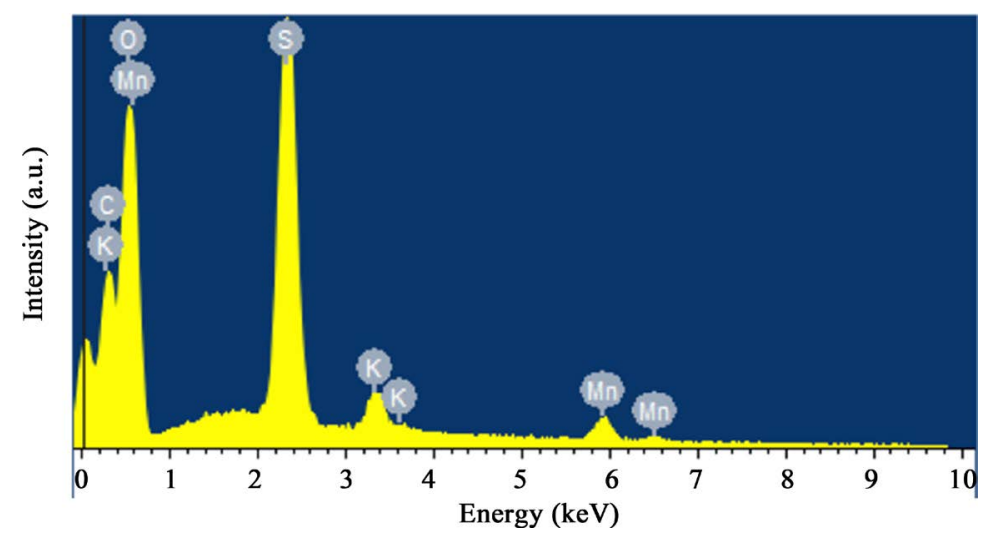

Figure 5. Energy-dispersive X-ray spectrum for graphene oxide.

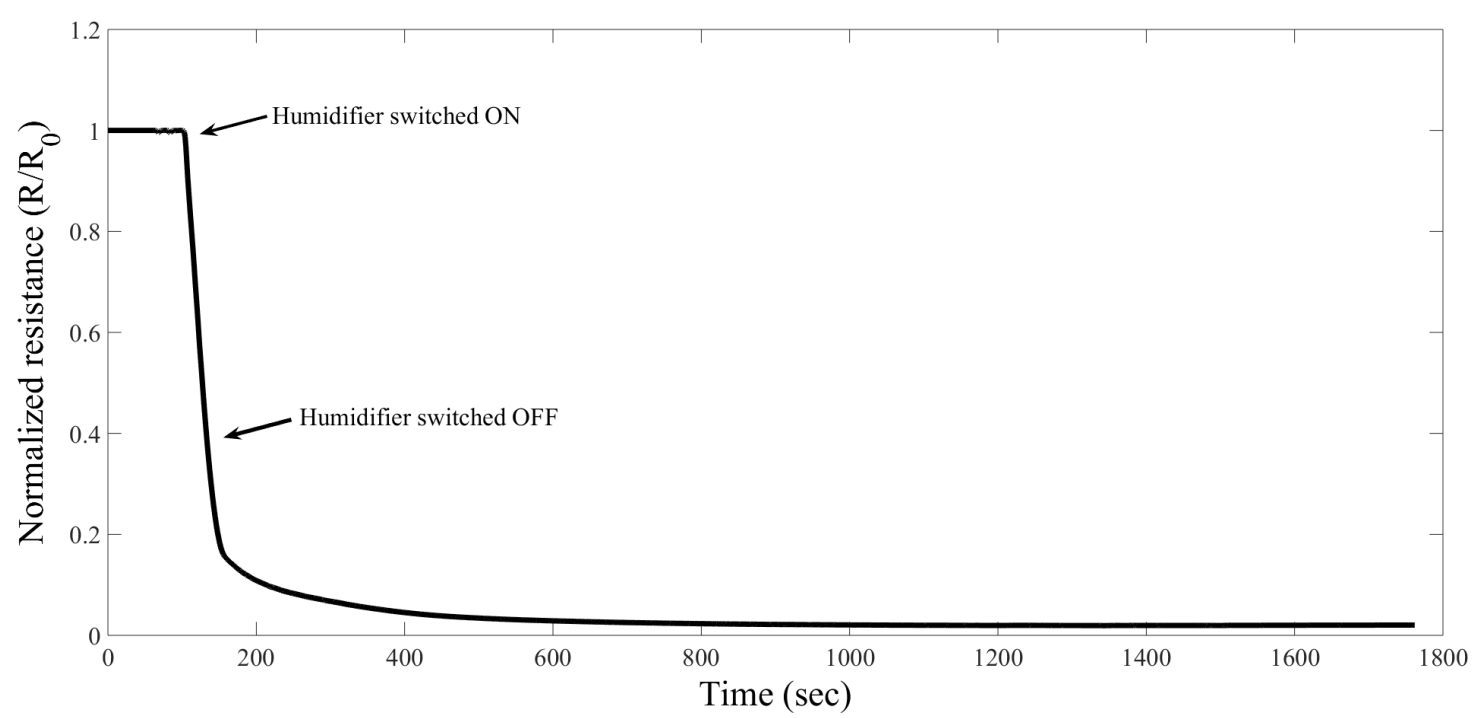

(a)

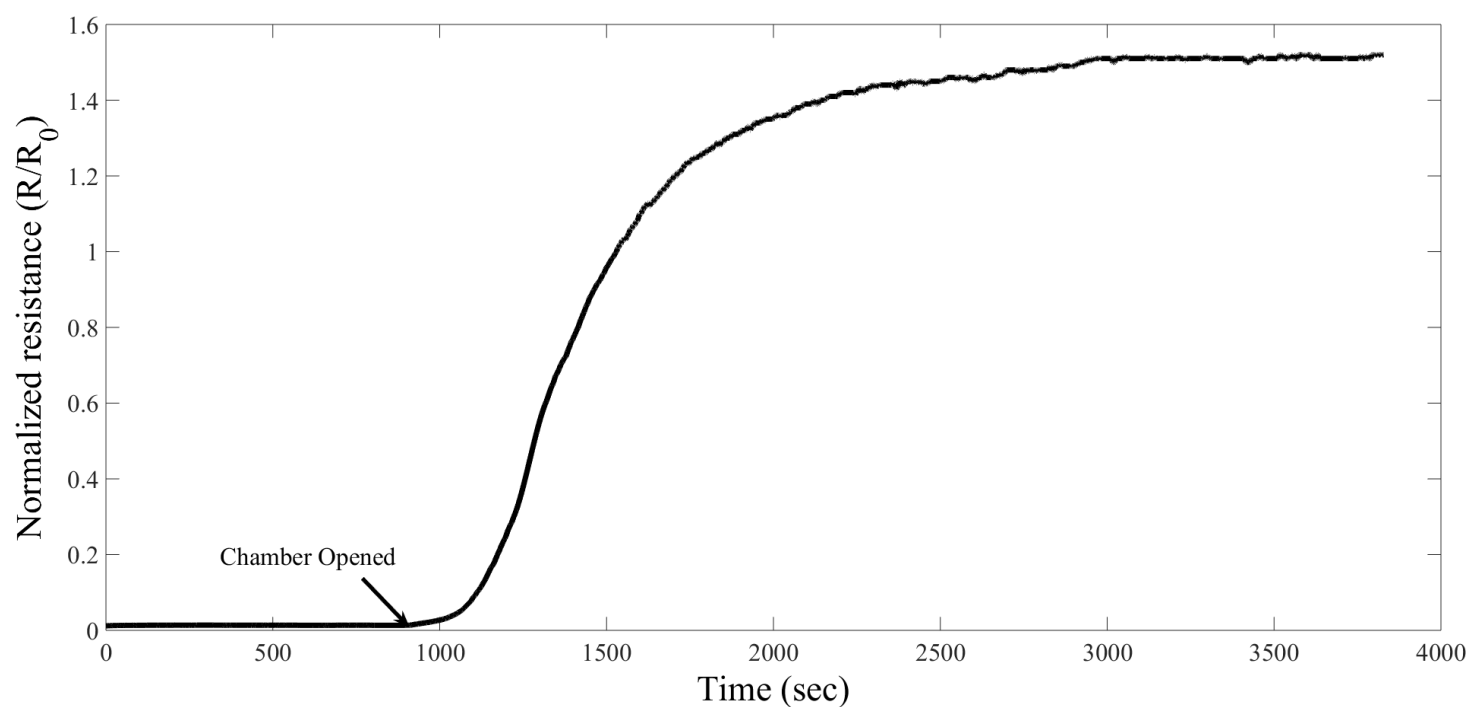

(b)

Figure 6. Time response of the humidity sensing device. (a) Humidity increased from $30 \%$ to $60 \%$; (b) Humidity decreased from $60 \%$ to $30 \%$. 
A large decrease in resistance ( $98 \%)$ is observed after exposure to humidity. This shows that water vapor is adsorbed on the surface of GO, which increases its conductivity drastically due to proton exchange. According to the literature, the response time is defined as the amount of time required for the impedance to change by $90 \%$ of the total impedance [29]. For the sensor exposed to $60 \% \mathrm{RH}$, the response time was about $100 \mathrm{~s}$. This compares well with the response times for other humidity sensors reported in the literature [30]-[32].

To study the performance of the sensor for decreasing humidities, the chamber was opened while at $60 \% \mathrm{RH}$. The humidity in the chamber decreased with time, and equilibrated with the room conditions of $30 \% \mathrm{RH}$. Figure 6(b) shows the time response of the sensor as the humidity decreases from $60 \%$ to $30 \% \mathrm{RH}$. The decrease in humidity inside the chamber causes an increase in resistance. The resistance is normalized to the resistance $\mathrm{R}_{0}$ of the GO device at the start of the entire experiment, i.e. before the humidity is increased from $30 \%$ to $60 \%$. It is observed that the resistance of the GO device after one cycle from $30 \%$ to $60 \% \mathrm{RH}$ and back is higher than its original resistance $\mathrm{R}_{0}$. This indicates that there is some vapor content that gets absorbed into the GO device, thereby increasing its resistance. It is therefore important to study the humidity hysteresis characteristics of these sensors.

Experiments were conducted for various conditions, with humidity varying from $30 \%$ to $95 \%$. Figure 7 shows a plot of resistance change as a function of RH. It is observed that the experimental data closely fits an exponential curve. Suri et al. define sensitivity $S$ as the ratio of resistance before humidity exposure and at a given $R H$ [33]. This does not take in to account the actual change in $\mathrm{RH}$ for a given change in resistance. We define sensitivity of the sensor $S$, as

$$
S=\frac{R_{0}-R_{h}}{R_{0} \times \Delta R H}=\frac{1-\frac{R_{h}}{R_{0}}}{\Delta R H}
$$

where $R_{h}$ is the resistance of the sensor at a given $\% R H, R_{0}$ is the resistance of the sensor at a reference humidity level, and $\Delta R H$ is the change in relative humidity from the reference humidity level. A higher value of $S$ relates to a higher sensitivity to humidity.

As is clearly observed from Figure 7, the sensor is highly sensitive at low changes in humidity. A maximum sensitivity of $7.9 \Omega / \Omega-\% R H$ is obtained for this sensor using our definition of sensitivity for reference humidity level of 30\%. Using the definition of sensitivity given by Suri et al., a sensitivity of 100 is obtained for a RH change of $65 \%$. This compares favorably with those obtained in previous works, $\sim 100$ for a RH change of $75 \%$ in [33] and 138 for a RH change of $78 \%$ in [32] (Table 2).

Table 3 shows a comparison of the sensing performance of this sensor against other graphene-based humidity

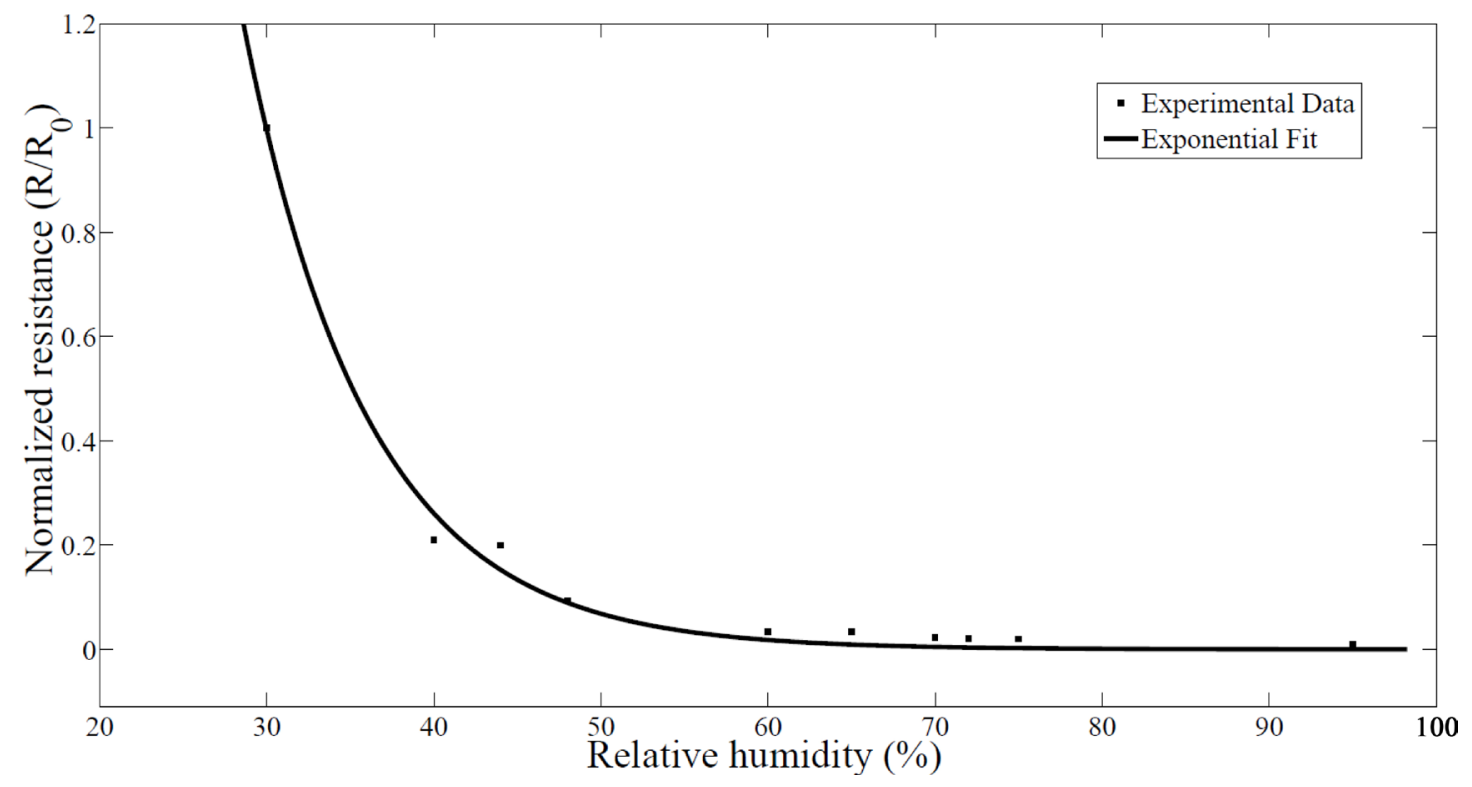

Figure 7. Resistance change variation with RH. 
Table 2. Comparison of sensitivity.

\begin{tabular}{cccc}
\hline & Current work & Ref. [32] & Ref. [33] \\
\hline $\mathrm{S}(\Omega / \Omega-\% \mathrm{RH})$ & 7.9 & 1.273 & 1.323 \\
$\mathrm{R}_{\mathrm{h}} / \mathrm{R}_{0}$ & 100 & 138 & $\sim 100$ \\
$\Delta \mathrm{RH}(\%)$ & 65 & 78 & 75 \\
\hline
\end{tabular}

Table 3. Comparison of sensing performance between the GO sensor and other graphene-based humidity sensors.

\begin{tabular}{ccccc}
\hline Sensing Material & Response time $(\mathrm{s})$ & Sensitivity $(\Omega / \Omega-\% \mathrm{RH})$ & $\Delta \mathrm{RH}(\%)$ & Reference \\
\hline GO & 100 & 7.9 & 65 & This work \\
Graphene-polypyrrole & 15 & 1.273 & 58 & {$[32]$} \\
Scotch-tape graphene & 600 & 0.714 & 70 & {$[18]$} \\
Reduced-GO & 50 & 0.514 & 54 & {$[19]$} \\
GO-silicon bilayer & 19 & 1.016 & 53 & {$[20]$} \\
\hline
\end{tabular}

sensors. Although the GO sensor has a slightly higher response time than some other sensors, the sensitivity of this sensor is much higher than most other graphene-based humidity sensors.

\subsection{Hysteresis}

Hysteresis is an important parameter to characterize the performance of humidity sensors. To examine this characteristic in the GO device, two sets of cyclic experiments were carried out. In the first case, the humidity was cycled between 30\% and 50\%, and between 30\% and 75\% in the second case. Figure 8 and Figure 9 show the time response of the device for these cases, respectively. In each case, the following procedure was followed: 1) the humidifier was switched $\mathrm{ON}$ to increase the humidity in the chamber to the required level, 2) the resistance was recorded for increasing humidity for $1200 \mathrm{~s}, 3$ ) the chamber opened to decrease the humidity to room conditions, 4) the resistance recorded for decreasing humidity for $1200 \mathrm{~s}$. This procedure is repeated for the required number of cycles.

Figure 8 shows the time response of the device for humidity ranging from $30 \%$ to $50 \%$. The sensing device shows high sensitivity, even for a $20 \%$ change in relative humidity. When the humidity is decreased to room conditions, the normalized resistance reaches $\sim 1$. This shows that there is weak interaction between the water molecules and the GO device for humidities $<50 \%$. Water molecules are primarily adsorbed on the surface of $\mathrm{GO}$, and hence the conductivity is dependent on water molecules on the GO surface. Most of the water molecules adsorbed on the GO surface are removed when the humidity is decreased to room conditions. When the experiment was cycled, similar trends in the resistance are observed. This demonstrated that the sensor response was highly reproducible at low humidities.

Similar cyclic experiments were done for humidity ranging from $30 \%$ to $75 \%$, results of which are shown in Figure 9. Unlike in the case of low humidities, the normalized resistance increases above 1 when the chamber humidity is decreased to room conditions. This increase continues for every cycle completed between $30 \%$ and $75 \%$. This can be attributed to water molecules getting absorbed into the GO thin film, entering the carbon interlayer, and forming bonds with the $\mathrm{C}-\mathrm{OH}$ and $\mathrm{C}=\mathrm{O}$ groups, resulting in an increase in interlayer spacing. This has also been speculated by Yao et al. [21].

To study the increase in hysteresis as a function of the number of cycles, experiments were conducted where the RH was cycled between $30 \%$ and $70 \%$. The resistance after absorption and desorption was monitored. Figure 10 shows the results of one such experiment. The linear increase in hysteresis is clearly observed with increase in number of cycles. Interestingly, as hysteresis increases, the sensitivity of the sensor increases linearly.

\subsection{Hysteresis Removal by Heating}

As shown earlier, the humidity sensor exhibits hysteresis, which increases with increasing number of cycles. To make the sensor more useful, it is imperative to "reset" the sensor by driving out the absorbed water molecules. In order to do this, the sensor, after exposure to $65 \% \mathrm{RH}$, is heated at $75^{\circ} \mathrm{C}$ for $30 \mathrm{~min}$. Figure 11 shows the 
response of the sensor before and after heating. The procedure is conducted twice to ensure that the sensor has repeatable performance even after a few reset cycles. The sensor shows similar response times before and after heating, as is clearly seen from the figure. Although the recovery response of the sensor changes slightly, the sensing response is fairly consistent.

\subsection{Sensing Mechanism}

Figure 12 illustrates the proposed sensing mechanism of GO. We propose that the change in resistance due to humidity is caused by the adsorption of water molecules on the surface of GO, as well as the absorption of water molecules into the GO thin film. The adsorption of molecules on the surface causes a change in resistance,

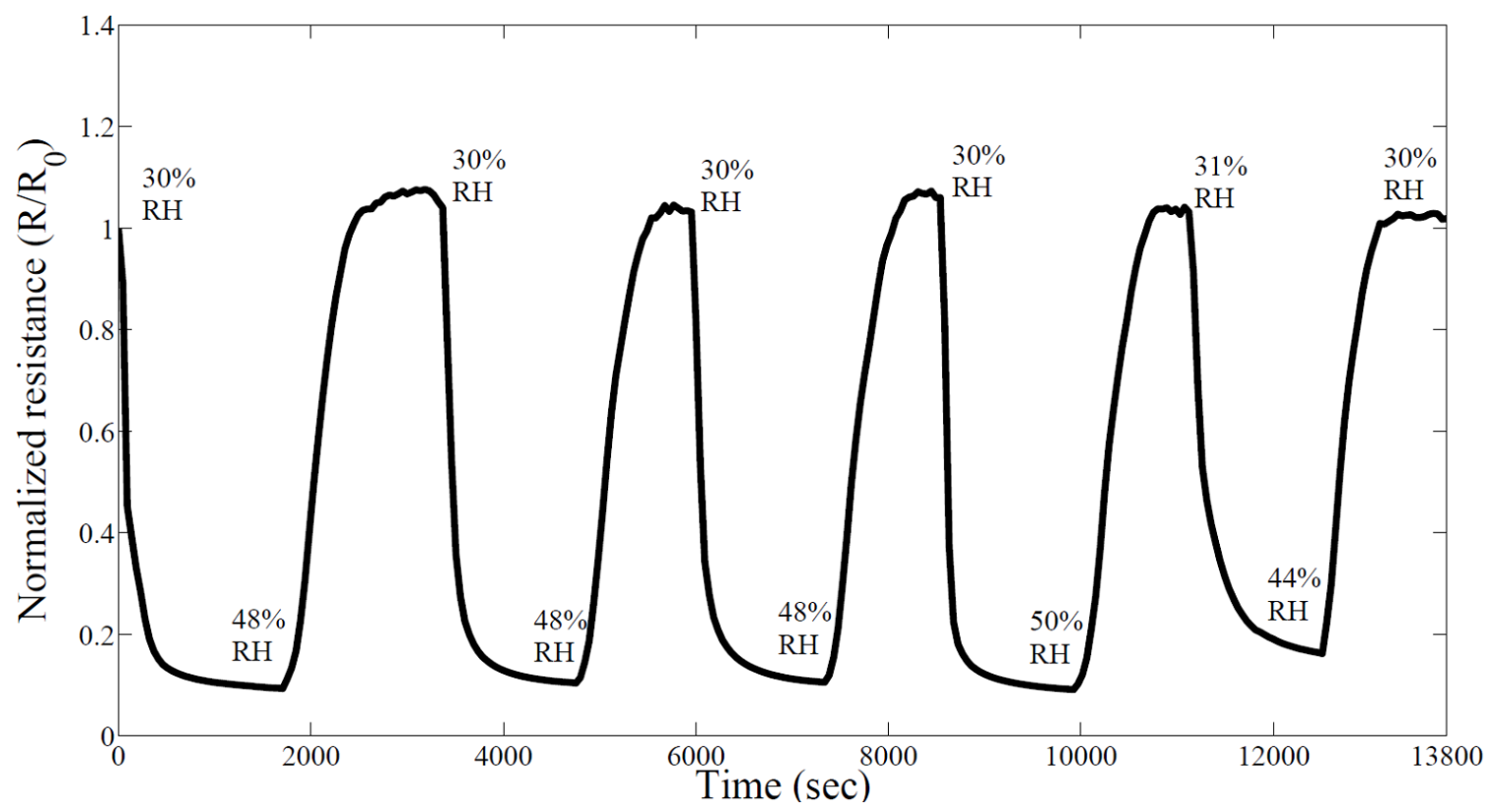

Figure 8 . Time response of the humidity sensing device, for humidity ranging from $30 \%$ to $50 \%$.

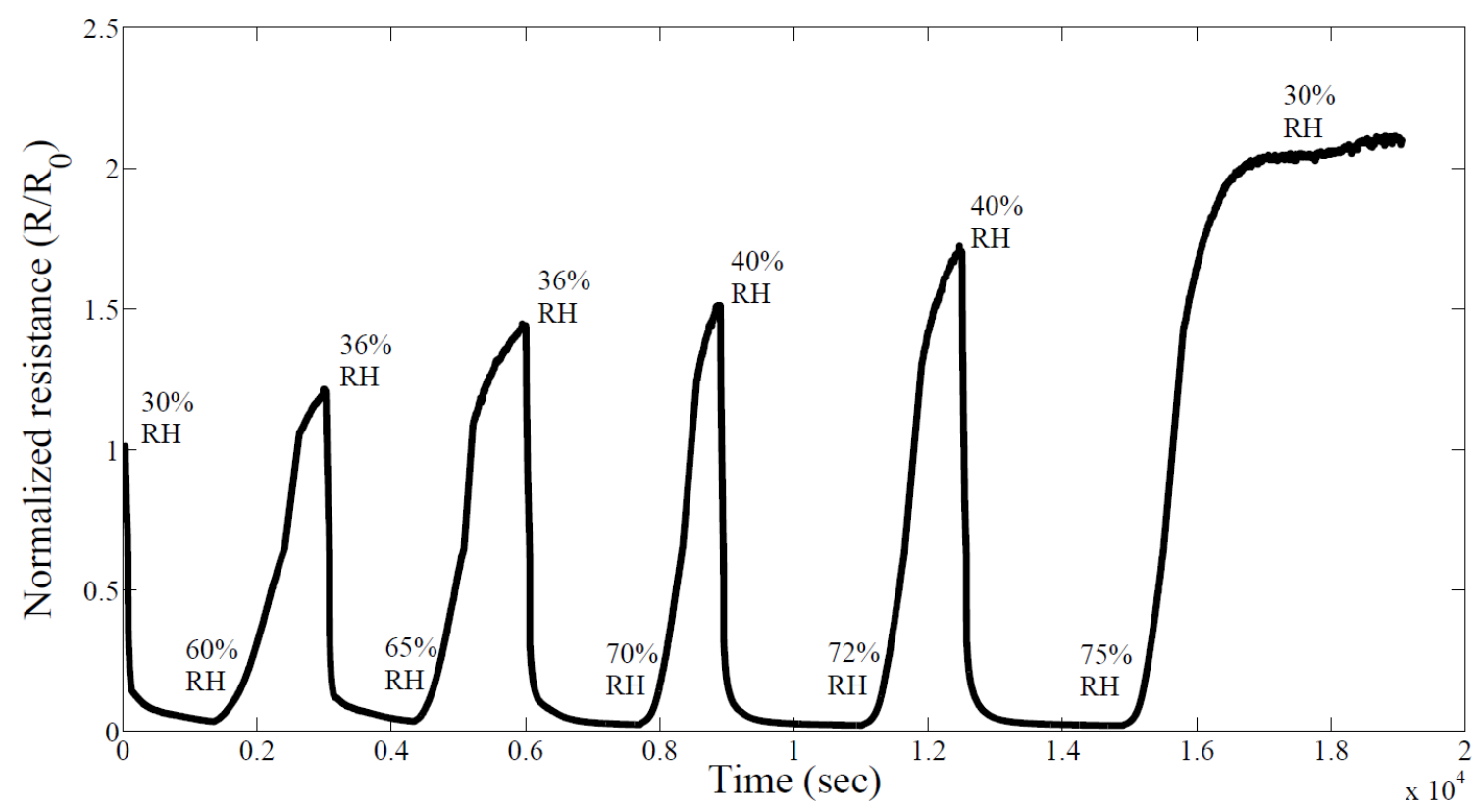

Figure 9. Time response of the humidity sensing device, for humidity ranging from $30 \%$ to $75 \%$. 


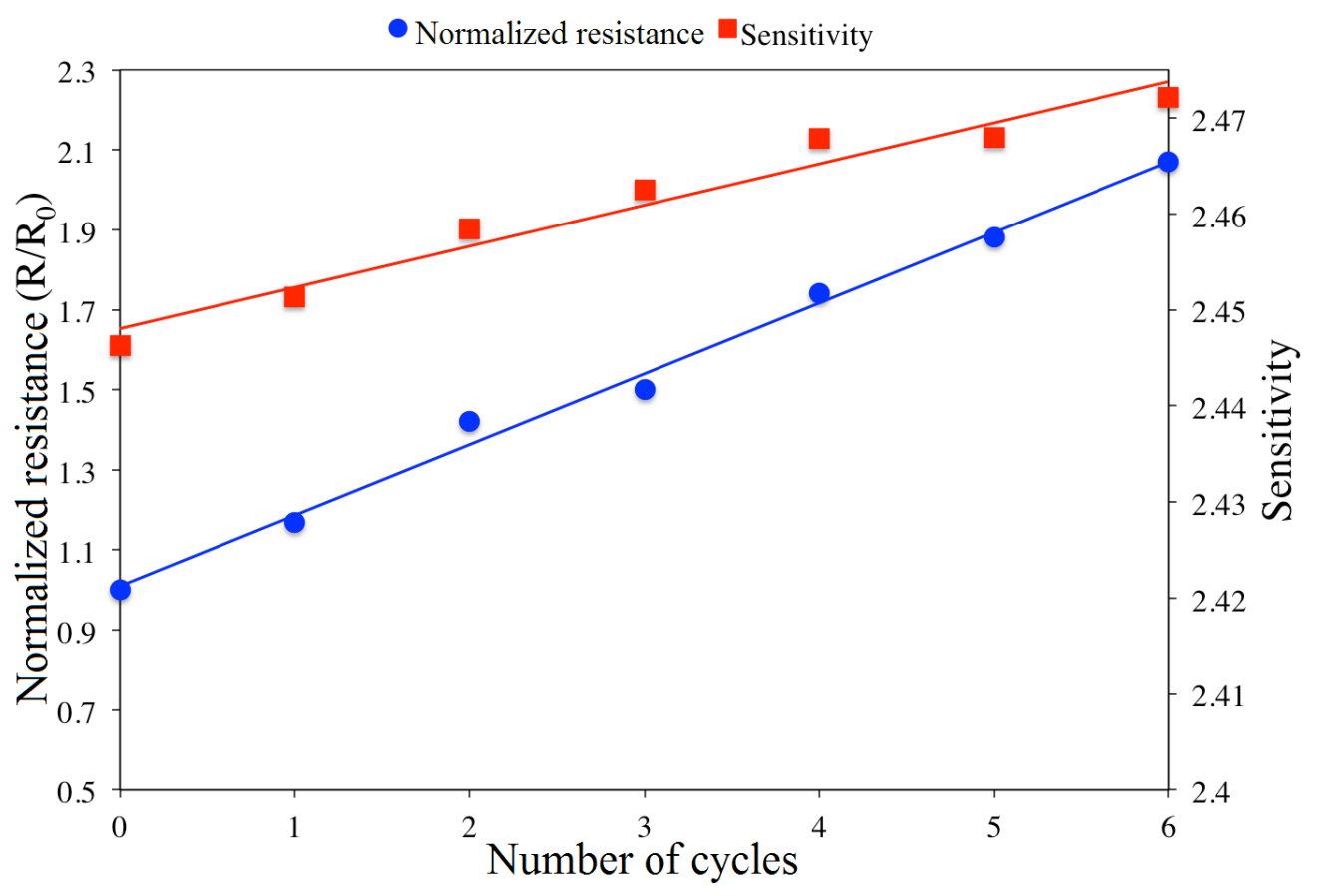

Figure 10. Hysteresis and sensitivity of humidity sensor as a function of number of cycles.

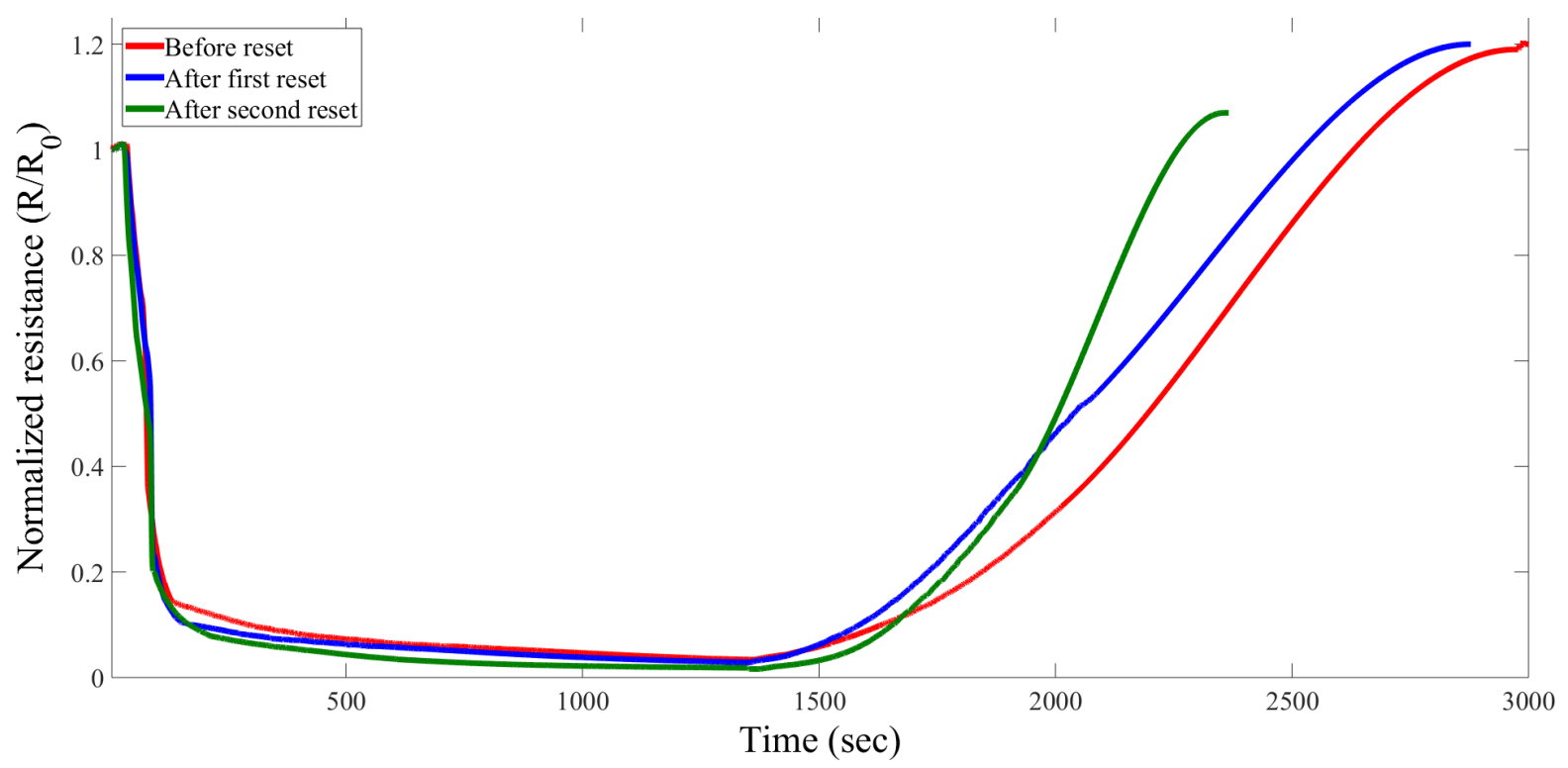

Figure 11. Sensor response before and after reseting.

which is due to proton-electron exchange between graphene oxide and the adsorbed molecules. In the case of water molecules on graphene oxide, the resistance decreases due to proton-exchange between graphene oxide and adsorbed water molecules. Similar mechanism was proposed by Anderson and Parks for the change in electrical conductivity of silica gel in the presence of adsorbed water [34].

Absorption of water molecules in graphene oxide causes an increase in resistance due to an increased interlayer spacing. Although these two mechanisms take place simultaneously, at low humidity, the adsorption mechanism results in a much larger decrease in resistance than the increase in resistance due to absorption of water molecules. At higher humidity, since more water molecules get absorbed into the GO thin film, there is a larger increase in resistance, which is clearly observed in the response curves shown previously. 


\section{Low RH}

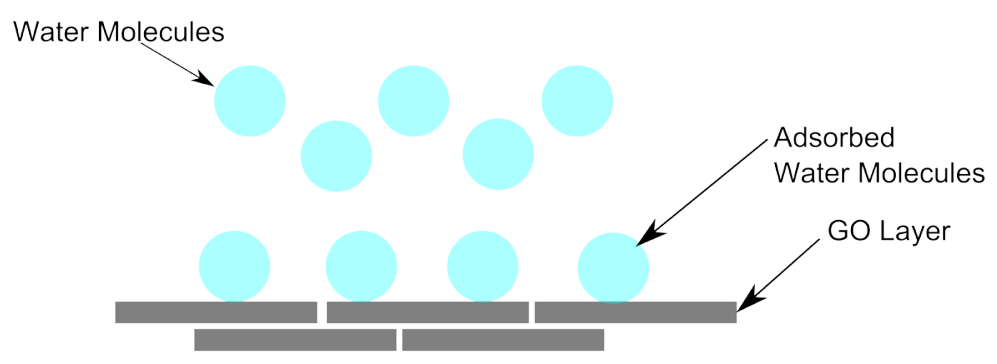

\section{High RH}

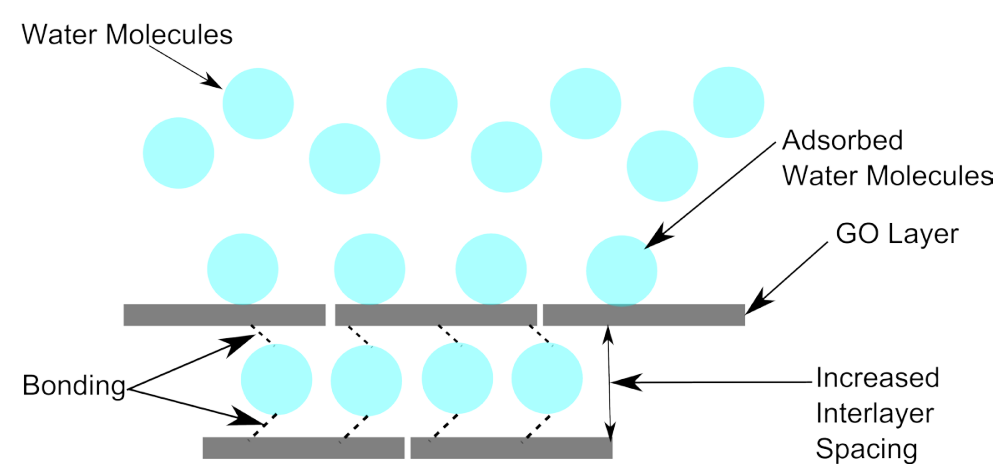

Figure 12. Sensor response before and after reseting.

To confirm the increase in interlayer spacing after exposure to high humidity, X-ray diffraction spectra were obtained for the GO device exposed to $75 \%$ RH. Figure 13 shows a comparison of the X-ray diffraction spectra of GO before and after exposure. The interlayer spacing is increased from $0.92 \mathrm{~nm}$ to $1.27 \mathrm{~nm}$. This increase in interlayer spacing, we propose, is due to the bonding between the dissociated $\mathrm{H}_{2} \mathrm{O}$ molecules $\left(\mathrm{H}_{2} \mathrm{O}=\mathrm{H}^{+}+\mathrm{OH}^{-}\right)$ and the $\mathrm{C}-\mathrm{OH}$ and $\mathrm{C}=\mathrm{O}$ groups of $\mathrm{GO}$. The increase in interlayer spacing is also consistent with previous studies on the interlayer spacing of graphene oxide as a function of relative humidity [35].

\section{Conclusion}

In this article, we reported on a room-temperature humidity sensing device using graphene oxide (GO) thin films fabricated by chemical exfoliation. The fabricated sensors showed excellent sensitivity to humidity, which is better than a lot of previous work in this area. The response of the sensor, although slightly slower than some other graphene-based humidity sensing systems, is still faster compared to most commercially available humidity sensors. The resistance change shows an exponential relation versus $\mathrm{RH}$ in the detection range of $30 \%$ to 95\%. Cyclic experiments conducted using the sensing device showed presence of humidity hysteresis at relative humidities higher than $50 \%$. A possible mechanism to explain this occurrence and to reset the sensor for reuse was proposed. A promising application of using graphene oxide as room-temperature humidity sensors was experimentally demonstrated.

\section{Acknowledgements}

This work was supported in part by the National Science Foundation through grant OISE-0730259, and in part by the Department of Transportation through the Infrastructure Technology Institute at Northwestern University. This work made use of the J.B.Cohen X-ray Diffraction Facility supported by the MRSEC program of the National Science Foundation (DMR-1121262) at the Materials Research Center at Northwestern University. The 


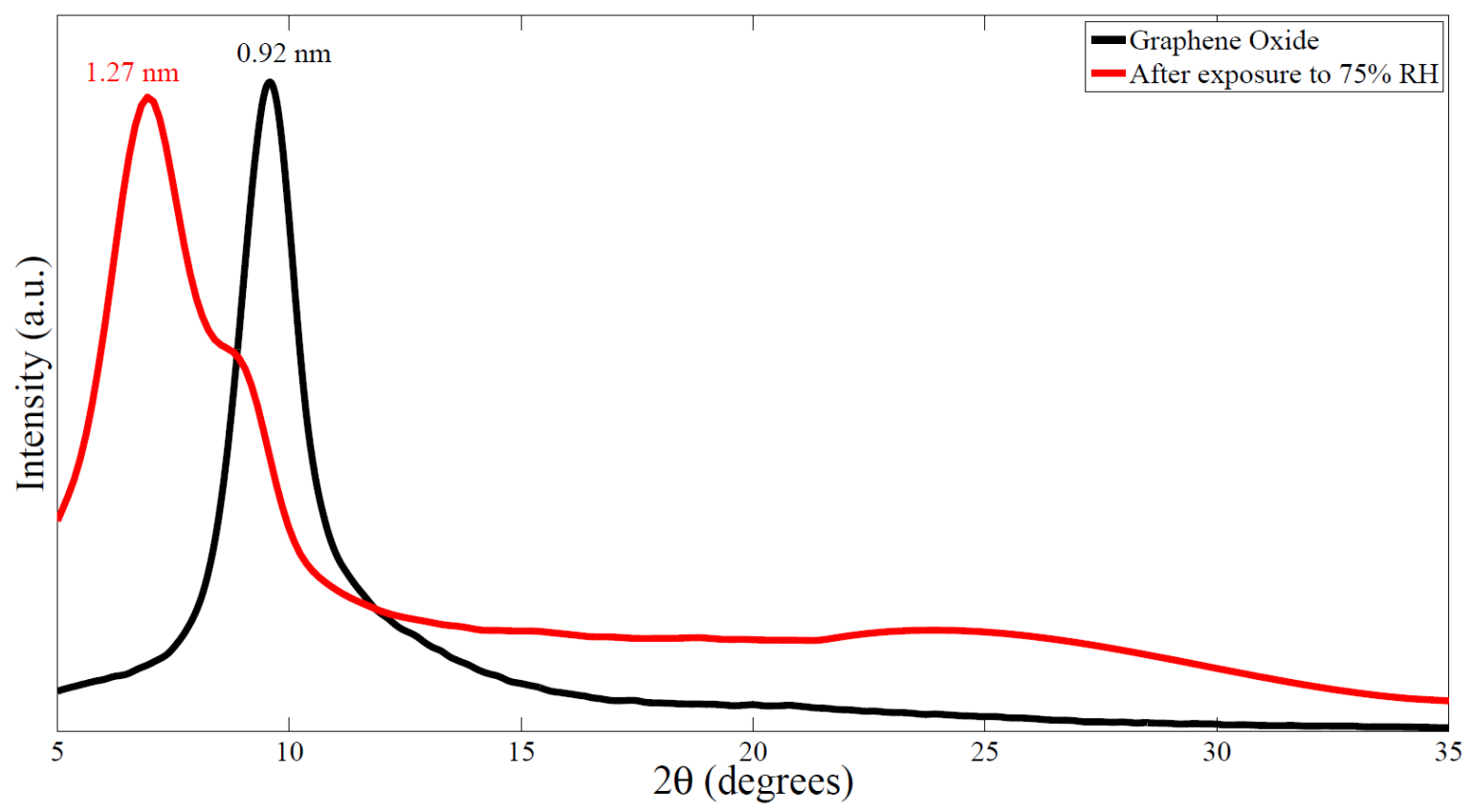

Figure 13. Comparison of XRD spectra before and after exposure to $75 \% \mathrm{RH}$.

SEM and Raman work was performed in the EPIC and KECK-II facilities of the NUANCE Center at Northwestern University. NUANCE Center is supported by NSF-NSEC, NSF-MRSEC, Keck Foundation, the State of Illinois, and Northwestern University.

\section{References}

[1] Si, S., Li, S., Ming, Z. and Jin, L. (2010) Humidity Sensors Based on ZnO Colloidal Nanocrystal Clusters. Chemical Physics Letters, 493, 288-291. http://dx.doi.org/10.1016/j.cplett.2010.05.013

[2] Zhang, Y., Yu, K., Jiang, D., Zhu, Z., Geng, H. and Luo, L. (2005) Zinc Oxide Nanorod and Nanowire for Humidity Sensor. Applied Surface Science, 242, 212-217. http://dx.doi.org/10.1016/j.apsusc.2004.08.013

[3] Yamazoe, N. and Shimizu, Y. (1986) Humidity Sensors: Principles and Applications. Sensors and Actuators, 10, 379398. http://dx.doi.org/10.1016/0250-6874(86)80055-5

[4] Erol, A., Okur, S., Comba, B., Mermer, O. and Arikan, M. (2010) Humidity Sensing Properties of ZnO Nanoparticles Synthesized by Sol-Gel Process. Sensors and Actuators B: Chemical, 145, 174-180. http://dx.doi.org/10.1016/j.snb.2009.11.051

[5] Su, P.-G. and Chang, Y.-P. (2008) Low-Humidity Sensor Based on a Quartz-Crystal Microbalance Coated with Polypyrole/Ag/TiO ${ }_{2}$ Nanoparticles Composite Thin Films. Sensors and Actuators B: Chemical, 129, 915-920. http://dx.doi.org/10.1016/j.snb.2007.10.006

[6] Zheng, S., Zhu, Y. and Krishnaswamy, S. (2011) Nanofilm-Coated Long-Period Fiber Grating Humidity Sensors for Corrosion Detection in Structural Health Monitoring. SPIE Proceedings, 7983, 79831A-79831A-9. http://dx.doi.org/10.1117/12.880478

[7] Novoselov, K.S., Geim, A.K., Morozov, S.V., Jiang, D., Zhang, Y., Dubonos, S.V., Grigorieva, I.V. and Firsov, A.A. (2004) Electric Field Effect in Atomically Thin Carbon Films. Science, 306, 666-669. http://dx.doi.org/10.1126/science.1102896

[8] Geim, A.K. and Novoselov, K.S. (2007) The Rise of Graphene. Nature Materials, 6, 183-191. http://dx.doi.org/10.1038/nmat1849

[9] Schedin, F., Geim, A.K., Morozov, S.V., Hill, E.W., Blake, P., Katsnelson, M.I. and Novoselov, K.S. (2007) Detection of Individual Gas Molecules Adsorbed on Graphene. Nature Materials, 6, 652-655. http://dx.doi.org/10.1038/nmat1967

[10] Lu, G., Ocola, L.E. and Chen, J. (2009) Reduced Graphene Oxide for Room-Temperature Gas Sensors. Nanotechnology, 20, 445502. http://dx.doi.org/10.1088/0957-4484/20/44/445502 
[11] Lu, G., Ocola, L.E. and Chen, J. (2009) Gas Detection Using Low-Temperature Reduced Graphene Oxide Sheets. Applied Physics Letters, 94, Article ID: 083111. http://dx.doi.org/10.1063/1.3086896

[12] Lange, U., Hirsch, T., Mirsky, V.M. and Wolfbeis, O.S. (2011) Hydrogen Sensor Based on a Graphene-Palladium Nanocomposite. Electrochimica Acta, 56, 3707-3712. http://dx.doi.org/10.1016/j.electacta.2010.10.078

[13] Nomani, M., Shishir, R., Qazi, M., Diwan, D., Shields, V., Spencer, M., Tompa, G.S., Sbrockey, N.M. and Koley, G. (2010) Highly Sensitive and Selective Detection of $\mathrm{NO}_{2}$ Using Epitaxial Graphene on 6H-SiC. Sensors and Actuators B: Chemical, 150, 301-307. http://dx.doi.org/10.1016/j.snb.2010.06.069

[14] Jeong, H.Y., Lee, D.-S., Choi, H.K., Lee, D.H., Kim, J.-E., Lee, J.Y., Lee, W.J., Kim, S.O. and Choi, S.-Y. (2010) Flexible Room-Temperature $\mathrm{NO}_{2}$ Gas Sensors Based on Carbon Nanotubes/Reduced Graphene Hybrid Films. Applied Physics Letters, 96, Article ID: 213105. http://dx.doi.org/10.1063/1.3432446

[15] Yoon, H.J., Jun, D.H., Yang, J.H., Zhou, Z., Yang, S.S. and Cheng, M.M.C. (2011) Carbon Dioxide Gas Sensor Using a Graphene Sheet. Sensors and Actuators B: Chemical, 157, 310-313. http://dx.doi.org/10.1016/j.snb.2011.03.035

[16] Robinson, J.T., Perkins, F.K., Snow, E.S., Wei, Z. and Sheehan, P.E. (2008) Reduced Graphene Oxide Molecular Sensors. Nano Letters, 8, 3137-3140. http://dx.doi.org/10.1021/nl8013007

[17] Hu, N., Wang, Y., Chai, J., Gao, R., Yang, Z., Kong, E.S.W. and Zhang, Y. (2012) Gas Sensor Based on P-Phenylenediamine Reduced Graphene Oxide. Sensors and Actuators B: Chemical, 163, 107-114. http://dx.doi.org/10.1016/j.snb.2012.01.016

[18] Massera, E., Ferrara, V.L.A., Miglietta, M., Polichetti, T., Nasti, I. and Francia, G.D.I. (2011) Gas Sensors Based on Graphene. Chemistry Today, 29, 39-41.

[19] Guo, L., Jiang, H.-B., Shao, R.-Q., Zhang, Y.-L., Xie, S.-Y., Wang, J.-N., Li, X.-B., Jiang, F., Chen, Q.-D., Zhang, T. and Sun, H.-B. (2012) Two-Beam-Laser Interference Mediated Reduction, Patterning and Nanostructuring of Graphene Oxide for the Production of a Flexible Humidity Sensing Device. Carbon, 50, 1667-1673. http://dx.doi.org/10.1016/j.carbon.2011.12.011

[20] Yao, Y., Chen, X., Guo, H., Wu, Z. and Li, X. (2012) Humidity Sensing Behaviors of Graphene Oxide-Silicon BiLayer Flexible Structure. Sensors and Actuators B: Chemical, 161, 1053-1058. http://dx.doi.org/10.1016/j.snb.2011.12.007

[21] Yao, Y., Chen, X., Guo, H. and Wu, Z. (2011) Graphene Oxide Thin Film Coated Quartz Crystal Microbalance for Humidity Detection. Applied Surface Science, 257, 7778-7782. http://dx.doi.org/10.1016/j.apsusc.2011.04.028

[22] Hummers, W. and Offeman, R. (1958) Preparation of Graphitic Oxide. Journal of the American Chemical Society, 80, 1339-1339. http://dx.doi.org/10.1021/ja01539a017

[23] Fan, Z.-J., Kai, W., Yan, J., Wei, T., Zhi, L.-J., Feng, J., Ren, Y.-M., Song, L.-P. and Wei, F. (2011) Facile Synthesis of Graphene Nanosheets via Fe Reduction of Exfoliated Graphite Oxide. ACS Nano, 5, 191-198. http://dx.doi.org/10.1021/nn102339t

[24] Cote, L.J., Cruz-Silva, R. and Huang, J. (2009) Flash Reduction and Patterning of Graphite Oxide and Its Polymer Composite. Journal of the American Chemical Society, 131, 11027-11032. http://dx.doi.org/10.1021/ja902348k

[25] Valles, C., David Nunez, J., Benito, A.M. and Maser, W.K. (2012) Flexible Conductive Graphene Paper Obtained by Direct and Gentle Annealing of Graphene Oxide Paper. Carbon, 50, 835-844. http://dx.doi.org/10.1016/j.carbon.2011.09.042

[26] Gomez-Navarro, C., Weitz, R.T., Bittner, A.M., Scolari, M., Mews, A., Burghard, M. and Kern, K. (2007) Electronic Transport Properties of Individual Chemically Reduced Graphene Oxide Sheets. Nano Letters, 7, 3499-3503. http://dx.doi.org/10.1021/nl072090c

[27] Schniepp, H.C., Li, J.-L., McAllister, M.J., Sai, H., Herrera-Alonso, M., Adamson, D.H., Prud’homme, R.K., Car, R., Saville, D.A. and Aksay, I.A. (2006) Functionalized Single Graphene Sheets Derived from Splitting Graphite Oxide. The Journal of Physical Chemistry B, 110, 8535-8539. http://dx.doi.org/10.1021/jp060936f

[28] Jeong, H.-K., Lee, Y.P., Jin, M.H., Kim, E.S., Bae, J.J. and Lee, Y.H. (2009) Thermal Stability of Graphite Oxide. Chemical Physics Letters, 470, 255-258. http://dx.doi.org/10.1016/j.cplett.2009.01.050

[29] Cho, J.-H., Yu, J.-B., Kim, J.-S., Sohn, S.-O., Lee, D.-D. and Huh, J.-S. (2005) Sensing Behaviors of Polypyrrole Sensor under Humidity Condition. Sensors and Actuators B: Chemical, 108, 389-392. http://dx.doi.org/10.1016/j.snb.2004.12.082

[30] Sun, A., Li, Z., Wei, T., Li, Y. and Cui, P. (2009) Highly Sensitive Humidity Sensor at Low Humidity Based on the Quaternized Polypyrrole Composite Film. Sensors and Actuators B: Chemical, 142, 197-203. http://dx.doi.org/10.1016/j.snb.2009.08.028

[31] Geng, W., Li, N., Li, X., Wang, R., Tu, J. and Zhang, T. (2007) Effect of Polymerization Time on the Humidity Sensing Properties of Polypyrrole. Sensors and Actuators B: Chemical, 125, 114-119. http://dx.doi.org/10.1016/j.snb.2007.01.041 
[32] Lin, W.-D., Chang, H.-M. and Wu, R.-J. (2013) Applied Novel Sensing Material Graphene/Polypyrrole for Humidity Sensor. Sensors and Actuators B: Chemical, 181, 326-331. http://dx.doi.org/10.1016/j.snb.2013.02.017

[33] Suri, K., Annapoorni, S., Sarkar, A. and Tandon, R. (2002) Gas and Humidity Sensors Based on Iron Oxidepolypyrrole Nanocomposites. Sensors and Actuators B: Chemical, 81, 277-282. http://dx.doi.org/10.1016/S0925-4005(01)00966-2

[34] Anderson, J.H. and Parks, G.A. (1968) The Electrical Conductivity of Silica Gel in the Presence of Adsorbed Water. The Journal of Physical Chemistry, 177, 3662-3668. http://dx.doi.org/10.1021/j100856a051

[35] De Boer, J. and Van Doorn, A. (1958) Graphite Oxide. V. The Sorption of Water. Koninklijke Nederlandse Akademie van Wetenschappen, Series B, 61, 242-252. 